\title{
Assessing the Relationship between Strategy and Organizational Culture in an Iranian Manufacturing Industry
}

\author{
Khaled Nawaser ${ }^{1}$, Fatemeh S. Shahmehr ${ }^{2}$, Azadeh Kamel $^{3} \&$ Seyed Mahdi Vesal $^{4}$ \\ ${ }^{1}$ Faculty of Management, Payam Noor University, Iran \\ ${ }^{2}$ Faculty of Entrepreneurship, University of Tehran, Iran \\ ${ }^{3}$ Electronic Business Management, Industrial Management Institute, Iran \\ 4 Department of Management, University of Nooretouba, Iran \\ Correspondence: Azadeh Kamel, Industrial Management Institute (IMI), Iran. Tel: 98-919-737-4071. E-mail: \\ azkkaa@yahoo.com
}

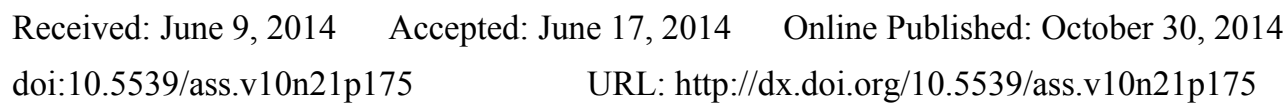

\begin{abstract}
Organizational culture and strategy are linked because organizational strategy can be devised by studying the organizational culture in place. In other words, organizational strategy is influenced by the culture set in the organization. Organizational culture and strategy are often part of the major contributing factors to how far a business will proceed. The purpose of this paper is to investigate the relationship between organizational culture and the competitive strategies in Iran-Khodro Automotive Company. The research was conducted in Iran-Khodro Automotive Company. The employees were considered as the population of the study and a questionnaire was designed for the purpose of data collection. Results show that there is a significant relationship between strategy and organizational culture. Considering a minor difference between differentiation and lower cost strategies, the company's strategies could be mentioned as a combination of the two. Furthermore, in terms of its competitive strategies, the company seems to pursue differentiation strategy rather than focus strategy. In addition, analysis of the company's organizational culture characteristics demonstrates that some of these characteristics are not in coordination with company's strategies in specific cases in the Company.
\end{abstract}

Keywords: strategy, competitive strategy, organizational culture, organizational change, Iran-Khordo automotive company

\section{Introduction}

The researches on the subject of organizational culture and its effect on other organizational variables became widespread during 1980s. Lund (2003) alludes to the fact that the 1980s witnessed a surge in popularity to examine the concept of organizational culture as managers became increasingly aware of the ways that an organizational culture can affect employees and organizations". Nowadays, no organization can go on its mission and last in the world of competition without maintaining a strong advantageous culture. The organizational changes are a long term and complicated process which requires extensive changes in all business facilities and infrastructures. The strategic management and planning is of the most important and well-known of evolutionary programs. Regarding the fact that almost all organizational evolutionary programs are going to change attitudes and internalize new values (in the form of new behaviors) in organization and among personnel. Organizational culture, as the infrastructure and the platform of organizational evolution, is the center of thinking for these programs. Without effective implementation of strategy, organizations will not be able to make use of benefits resulted from the outcomes of designed strategies. On the other words, assuring the success of organizational evolution depends upon prepared background and organizational culture. Organizational culture is double-edged sword. It means that it is a platform which facilitates achieving the organizational aims in one hand and it can be a hinder against applying changes in the organization on the other hand.

Thus, the judgment criteria about a culture can be considered as the rate of its coordination with objectives and strategies of that organization. Therefore, regarding the importance and necessity of this issue, the researcher is going to determine the relation between strategy and organizational culture considering the Porter's generic 
competitive strategies and reviewing the related literature about models of organizational culture. This is carried out by formulating a major question and three minor questions as the followings:

\section{Major Question:}

- Is there any relation between strategy and organizational culture?

Minor Questions:

- What relation is there between cost leadership strategy and organizational culture?

- What relation is there between differentiation strategy and organizational culture?

- What relation is there between concentration strategy and organizational culture?

\section{Literature Review}

A company with a weak to nonexistent culture is bound to either meander along or to be stifled by competitors with a dominant culture. In contrast, a company with an established culture often chooses its employees based on the fact that they share the same values, making them a cohesive entity. This link between organizational culture and strategy can be seen in a top financial management company with a strong corporate culture of hiring young, energetic, brilliant committed employees who help drive the company to succeed. The organization has six lateral dimensions including strategy, culture, size, technology, environment (background dimensions) and structure (structural dimensions) which are seemed as the personality and physical traits of the organization. Meanwhile, the background dimensions are signifiers of whole organization as they depict organization and its environment along each other as they can be considered as a set of overlap factors which compose the total foundation and processes of an organization (Markides, 1999; Jahanshahi, et al., 2011a).

Organization strategy shows competitive targets and techniques which signifies it from other organizations. The word strategy borrowed from Greek word 'Strategema' means army commander. According to Aristotle, the aim of strategy is victory. It means that strategy means an activity or program applying to win something (Davari and Shanehsazzade, 2001; Jahanshahi, et al., 2011b; Moezzi, et al., 2012). Sun Tzu was the first great inventor who had used strategy in his thesis entitled the art of fighting in its military sense as a technique or art of planning, combining and mixing military operation to win a recognized war target (Collins, 1981). But after industrial revolution in nineteenth century in Europe, the traditional concept of strategy was changed as the other aspects than military aspect had been added to it (Beyan, 1999, Vesal, et al., 2013). The concept of strategy had been entered to management culture from fiftieth decade when rhetoricians of natural systems had entered the nature factor in studying organizations (Ansef and McDonnell, 1996). Various definitions had been presented by different thinkers of management up to present. Minterberg is of those people who have stated that no one can present a special meaning for strategy as he believed that it should be analyzed from different aspects in order to understand it. He is of opinion that the concept of strategy is a combination of different attitudes and theories which are presented about strategy and expanded based on the schools of strategy. He introduced five concepts for strategy which are known as Five P Model (Henry Mintzberg et al., 2003). In a competitive market, an organization shapes its corporate structure in such a manner as to enable it come up with the best competitive strategy. As such, if the company has a strong culture, this can lead to increase in productivity that can be leveraged to a corporate strategy. (Erabi, 2006; Dehkordy, et al., 2013; Nawaser, et al., 2011a; Jahanshahi, et al., 2011c).

Totally, strategies of every organization can be classified into three organizational hierarchies. These levels include: company strategy, business strategy and duty strategy. It concentrates on the improvement of competitive condition of a company or firm in an industry or a special market. Totally, the business strategy can be competitive (fighting against all competitors for gaining profit) or cooperative (co-operating with one or more competitors to cope with them) or a combination of both (Sadeghi et al., 2013; Jahanshahi et al., 2011d).

According to Porter, the best way for describing the type of an activity which a company accomplishes is to describe it by a value chain. Figure 1 shows Porter's value chain. All companies or organizations which are particularly active in an industry have the same value chain (David, 2007). Value chain analysis can be very important for identifying the place and process in all stages of value chain or in internal or external relations (Campbell, 2003).

According to Henderson, there is always competition for rare resources and the present documents signifies that it will go on in the future, too (Rahmanseresht, 2004). Nowadays, we have faced with saturation conditions in major markets of different industries. In addition, the removal of domain classifications of competition intensifies this fact more than ever. Small companies will find opportunity to compete with big companies in a 
competitive environment without domain classification and in most of cases they achieve great successes, too. This is a fact that there is no any secure area for business nowadays. Competitive strategy creates a defendable condition in an industry in which a company can cope with its competitors. In the other words, competitive strategy signifies a distinct method which a company wants to use for achieving success in each scopes of its strategic business.

\begin{tabular}{|c|c|c|c|c|c|c|}
\hline \multirow{3}{*}{$\begin{array}{c}\text { Support } \\
\text { Processes }\end{array}$} & \multicolumn{5}{|c|}{ Firm infrastructure: General Management, Planning Management, Legal, Finance, Accounting } & \multirow{5}{*}{$\begin{array}{l}\text { Competitive } \\
\text { Advantage }\end{array}$} \\
\hline & \multicolumn{5}{|c|}{ Human Recourse Management: Recruitment, Retention, Training, R\&D } & \\
\hline & \multicolumn{5}{|c|}{ Technology development: Continuous improvement in printing \& finishing assets } & \\
\hline & \multicolumn{5}{|c|}{ Procurement of Recourses: Purchasing paper, Printing consumables and other finishing consumables } & \\
\hline $\begin{array}{c}\text { Primary } \\
\text { Business } \\
\text { Processes }\end{array}$ & $\begin{array}{l}\quad \text { Inbound } \\
\quad \text { Logistics } \\
\text { - Reception } \\
\text { - Storages } \\
\text { - Inventory control } \\
\text { - Transportation planning }\end{array}$ & $\begin{array}{l}\text { Operations } \\
\text { - Printing } \\
\text { - Finishing }\end{array}$ & $\begin{array}{l}\quad \begin{array}{c}\text { Outbound } \\
\text { Logistics }\end{array} \\
\text { - Warehousing } \\
\text { - Order fulfilment } \\
\text { - Transportation } \\
\text { - Distribution } \\
\end{array}$ & $\begin{array}{l}\text { Marketing and } \\
\text { Sales } \\
\text { - Partnership } \\
\text { - Advertising } \\
\text { - Promotion }\end{array}$ & $\begin{array}{l}\text { Service } \\
\text { - Customer } \\
\text { support }\end{array}$ & \\
\hline
\end{tabular}

Figure 1. Porter's Value Chain ( David, 2007)

Michael Porter has suggested two types of strategies which are known as 'Generic Competitive Strategies' in order to cope with competitive companies in an industry. They include lower cost strategy and differentiation of product strategy. They are called generic strategies because every trade company of any type and size even nonprofit organizations can make use of these strategies (Erabi, 2006).

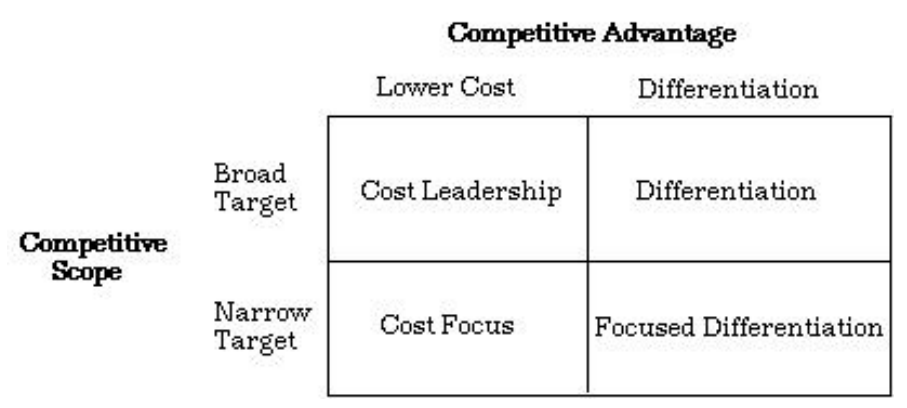

Figure 2. Porter's competitive strategies

- Lower Cost strategy refers to the ability of a company or a firm in designing, producing and marketing a product in a more effective way than its competitors. Competition is based on organizing and managing the business activities in this strategy (Aliahmadi, 2006; Nawaser et al, 2011b; Eizi, et al., 2013)

- Differentiation Strategy refers to the ability of presenting a unique and higher value to buyers. This strategy concentrates on some basics of product differentiation such as flexibility, special features, accessibility and so on. If the differentiation strategy is performed successfully, it will give the company an opportunity to ask for higher prices for its products (Scholl, 1998).

In addition, Porter is of opinion that competitive advantage of a company in an industry is determined by the competitive scope of that company. Competitive scope refers to the scope of the target market of a firm. A company or a firm can select an extensive or a limited market.

When two mentioned strategies are concentrated on a recognized part of market, it is called concentration strategy. The logic of this method is based upon the essence that paying attention to a limited number of products or target market will result in better and more accurate service presentation (Aliahmadi, 2006; Jahanashahi, et al., 2010; Hashemzadeh et al., 2011). The combination of these two target markets with the two mentioned competitive strategies lead to the creation of four types of strategies including cost leadership strategy, cost concentration strategy, differentiation concentration strategy which are depicted in figure 2 (Erabi, 2007) Figure 
3 signifies the simplified concept of cost leadership and differentiation strategy. Moreover, the effective competition in market requires having competitive advantage and competitive advantage is built on the platform of key qualifications which vary based on the type of issued strategy in the organization (Campbell, 2003).

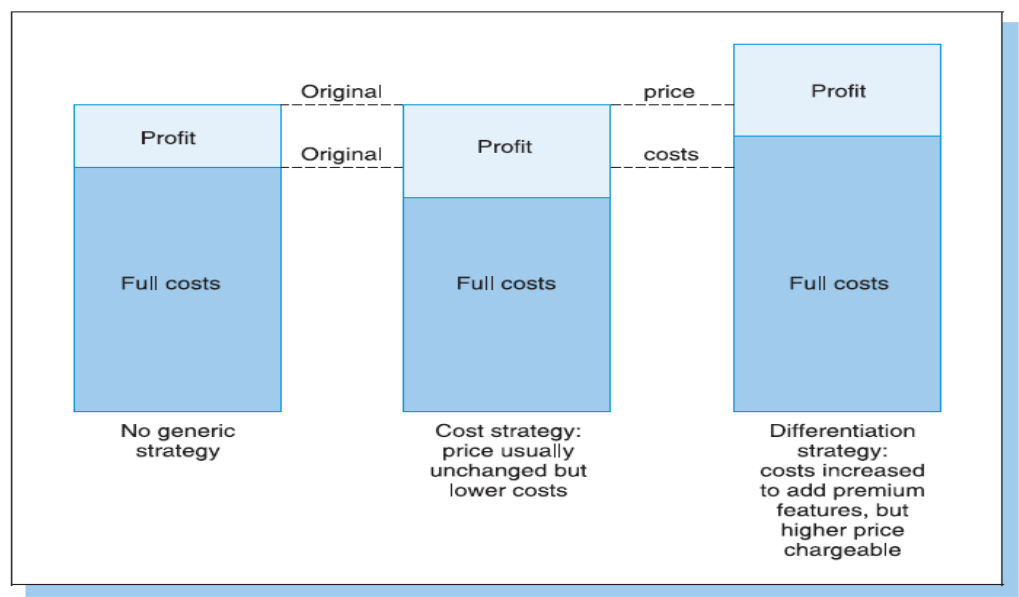

Figure 3. Simplified understanding of cost and differentiation strategies Campbell et. al. 2003

Organizational culture and strategy are part of the major factors to how far a business will go. Organizational culture is a new thought composing of two words or concepts of organization and culture in which none of these words signifies it separately (Toosi, 2000). The concept of organizational culture had been introduced in early 80 decade for the first time when Americans have tried to find and explained the success of Japanese in the international competition arena (Schneider \& Barco, 2000). Before that, it had seemed that organizations are intellectual instruments for establishing cooperation and controlling people in order to achieve the set goals but it worth mentioning that organizations are nothing beyond that. Organizations have personality just like humans (Asemipour, 1996; Khaksar, et al., 2011; Jahanshahi 2012).

Organizational culture has elements which cannot be defined in a tangible way. However, they are effective on groups and people's behavior in organization (Zomorodian, 1994). Most of researchers believe that these essential assumptions are values, norms, ages and formalities (Iranzade, 1997). Organizational culture have been modeled and classified based on various factors and traits till date. The two applied models in this research will be introduced and explained as the followings.

\subsection{Organic-Mechanical Model}

The canon of this model is the very important and essential factor of environment. According to the matrix of this model, simple or complex environment and rapid or slow environmental changes lead to appearance of four organizational structures for each one of the environments (and consequently four corresponding organizational cultures). The pioneers of this theory were Burner and Stalker who had introduced two distinct structures (machinery and organic) by studying twenty English and Scottish companies. They believed that the most effective structure is a structure which can adapt itself with environmental necessities. This thought shows the contingency attitude towards the organization (Robbins, 1999).

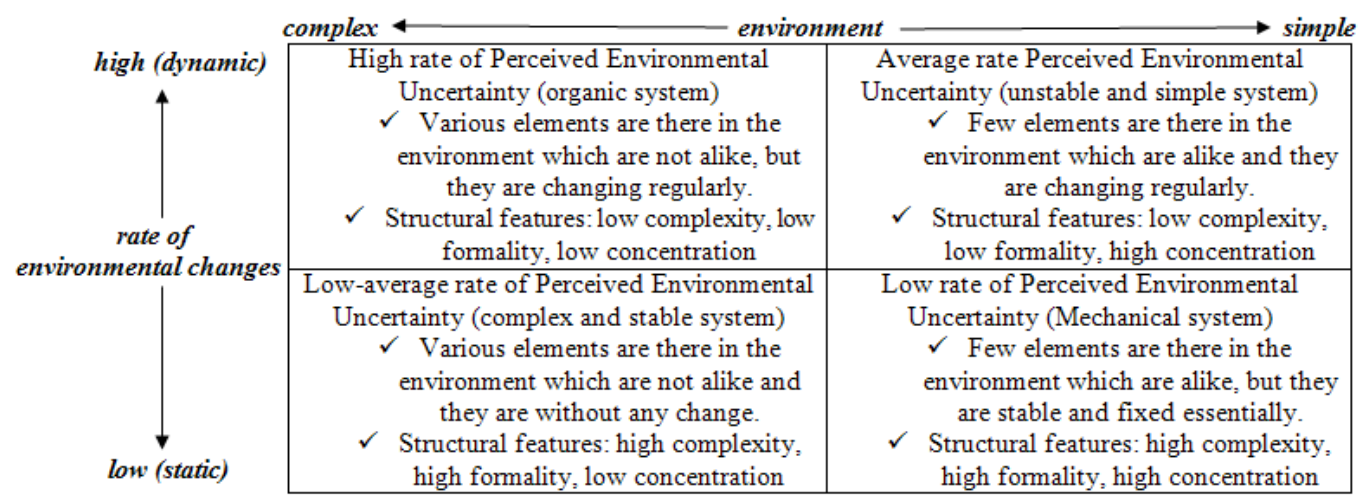

Figure 4. Matrix of Organic-Mechanical Model (Stephen P. Robbins, 1990) 


\subsection{Robbins Model}

According to Robbins, culture refers to essential dimensions and characteristics which are in relation with each other closely and have interactional dependencies. He is of opinion that if there will be a culture that can be discussed, it should have definable, recognized and measurable dimensions. Therefore, the presented model by Robbins points out the ten lateral criteria which are combined and mixed with each other. The essence of culture composes an organization (Robbins, 2001). The elements of Robbins model include creativity, risk taking, direction, unity and coherence, management support, control, identity, reward system, handling conflict and organizational communication. Each one of the mentioned characteristics is on a spectrum in Robbins model and refers to structural and behavioral dimensions simultaneously (Robbins, 1999). A small part of this fact that cultures are not the crystallization of personality and attitude of its members directly is due to this reason that a huge part of organization culture is related to structural variables directly (Robbins, 2001).

Strategic management helps the change process via defining the strategic aims, identifying opportunities and threats, analyzing and interpreting the change facilities, establishing balance between changes and the organization strategies and finally Business Process Reengineering (BPR) (Osterwalder \& Pringneur, 2002; Hakkak, et al., 2014). On the other hand, cultural methods play an effective role in strategic management, too. This fact is completely obvious in the fourth step (performing strategy) of strategic management particularly; that is so because aligned effective factors in performing strategic program will reinforce the strategic movement of the organization in accessing its perspective (Nixon, 2004) Figure 5 depicts this deviation.

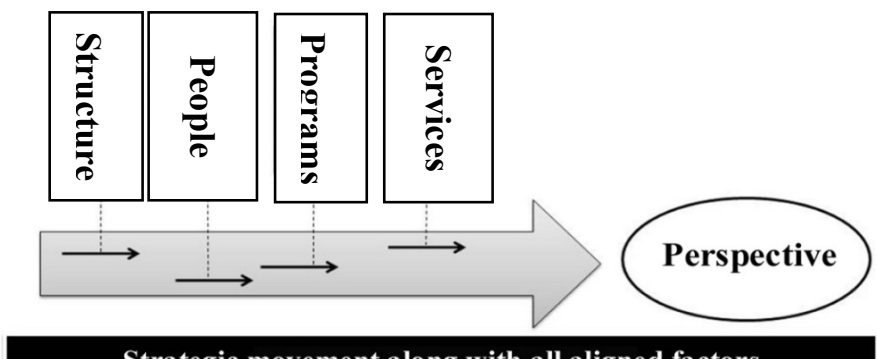

Strategic movement along with all aligned factors

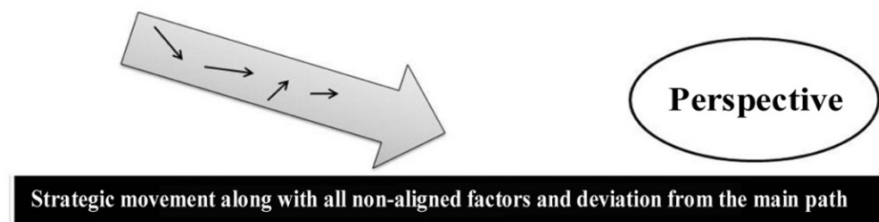

Figure 5. Role of aligned and unaligned factors in strategic movements of organization (Len Nixon, 2004)

\section{Methodology}

This research is an applied as far as the aims and objectives are concerned and it is a descriptive-case study as far as the nature of the research is concerned. The scope of this research is limited to Iran-khodro Company in the capital city of Tehran. This research was carried out from 2008 to 2009. The research statistical population includes all personnel of Iran-Khodor Company including 320 persons. Sample was selected via simple random sampling method and Morgan Statistical table, the sample size is 175 persons and the completed questionnaires were collected from all 175 individuals. In field studies, the two-part researcher-made questionnaire was used. The first part of questionnaire was related to background information which included five questions and the second part was known as understanding organizational culture-strategy which included four close type questions. The questions range was designed based on the Likert Five lateral Spectrum (Spectrum 1 to 5). The researchers made use of university professors, experts and specialists' viewpoints for the purpose of proving reliability and validity of the questionnaire. The research tools were found to possess a desirable validity as the calculated Cronbach Alfa is 0.87 .

\section{Results}

Multilateral linear regression analysis was used in order to analyze the relation between strategy (based on Porter's competitive strategies model) and organizational culture. The results of the test and calculated regression coefficients are mentioned in table 1 and 2 respectively. The findings of this test show that at least one of Porter's competitive strategies is meaningfully effective $\left(\mathrm{P}_{\text {Value }}<0.05\right)$ on organizational culture. 
Table 1. Regression analysis of the effects of Porter's competitive strategies on organizational culture

\begin{tabular}{cccccc}
\hline Source of Change & Total Squares & Freedom Degree & Mean Squares & $\mathrm{F}$ & $\mathrm{P}_{\text {Value }}$ \\
\hline Regression & 36.83 & 3 & 12.27 & 66.78 & $<.001$ \\
Remained & 27.39 & 150 & 0.17 & & \\
Total & 64.19 & 151 & & & \\
\hline
\end{tabular}

Table 2. Calculated Regression Coefficients

\begin{tabular}{ccccccc}
\hline & \multicolumn{2}{c}{ Non-Standardized Coefficient } & \multirow{2}{*}{ Standardized Coefficient } & \multirow{2}{*}{$\mathrm{T}$} & $\mathrm{P}_{\text {Value }}$ \\
\cline { 2 - 3 } & Standard Error & Coefficient & & & & \\
\hline Intercept & 0.217 & 0.487 & 0.27 & 0.025 \\
Differentiation & 0.059 & 0.436 & 0.125 & 0.135 & 7.45 & $<.001$ \\
Lower Cost & 0.055 & 0.307 & 0.284 & 2.34 & 0.020 \\
Concentration & 0.073 & 0.28 & $<.001$ \\
\hline
\end{tabular}

Simple linear regression analysis was used in order to analyze the relation between Lower Cost strategy and organizational culture. The outcomes are mentioned in table 3. The findings of this test show that there is a meaningful linear relation between lower cost strategy and organizational culture. In addition, the data transmittance related to lower cost strategy in relation with organizational culture is shown in diagram 1.

Table 3. Regression analysis of the effects of lower cost strategy on organizational culture

\begin{tabular}{|c|c|c|c|c|c|}
\hline \multicolumn{2}{|c|}{ Variance Analysis } & \multicolumn{2}{|c|}{ Parameters Calculations } & \multirow{2}{*}{$\begin{array}{c}\text { Pearson Correlation } \\
\text { Coefficient (r) }\end{array}$} & \multirow{2}{*}{$\begin{array}{c}\text { Coefficient of } \\
\text { Determination }\left(\mathrm{R}^{2}\right)\end{array}$} \\
\hline$(151,1) \mathrm{F}$ & $\mathrm{P}$ & Intercept & Slope & & \\
\hline 20.95 & $\mathrm{p}<.001$ & 2.212 & 0.328 & 0.359 & $12.1 \%$ \\
\hline
\end{tabular}

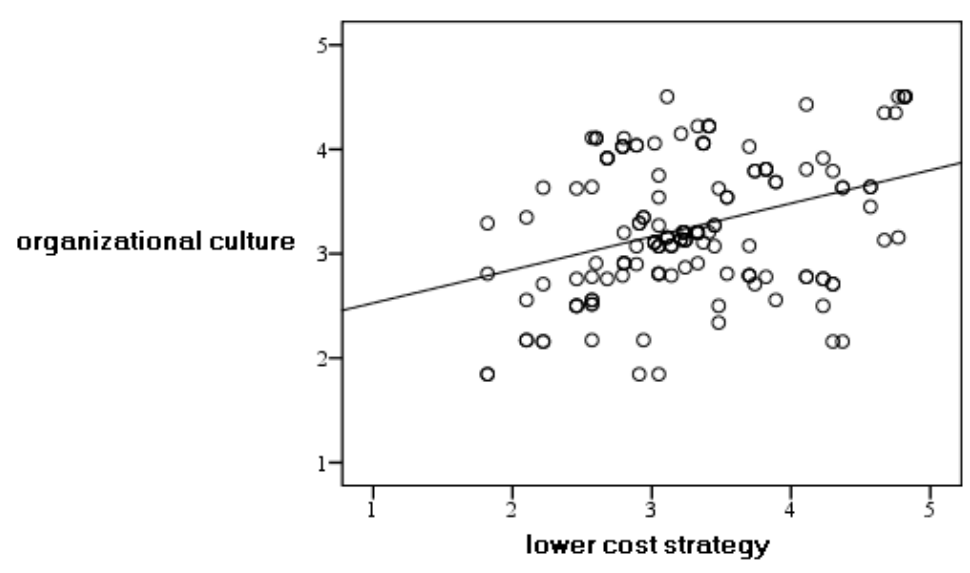

Diagram 1. Data transmittance related to lower cost strategy in relation with organizational culture

Simple linear regression analysis was used in order to analyze the relation between differentiation strategy and organizational culture. The results are mentioned in table 4.

Table 4. Regression analysis of the effects of differentiation strategy on organizational culture

\begin{tabular}{ccccccc}
\hline \multicolumn{2}{c}{ Variance Analysis } & \multicolumn{2}{c}{ Parameters Calculations } & & Pearson Correlation & Coefficient of \\
\cline { 1 - 3 }$\left({ }_{(151,1)} \mathrm{F}\right.$ & $\mathrm{P}$ & Intercept & Slope & & $\begin{array}{c}\text { Coefficient }(\mathrm{r}) \\
\text { Determination }\left(\mathrm{R}^{2}\right)\end{array}$ \\
\hline 142.02 & $\mathrm{p}<.001$ & 1.171 & 0.654 & & 0.685 & $49.3 \%$ \\
\hline
\end{tabular}

The findings of this test show that there is a meaningful linear relation between differentiation strategy and organizational culture. In addition, the data transmittance related to differentiation strategy in relation with organizational culture is shown in diagram 2.

Simple linear regression analysis was used in order to analyze the relation between Concentration strategy and organizational culture. The outcomes are mentioned in table 5. The findings of this test show that there is a meaningful linear relation between concentration strategy and organizational culture. In addition, the data transmittance related to concentration strategy in relation with organizational culture is shown in diagram 3. 


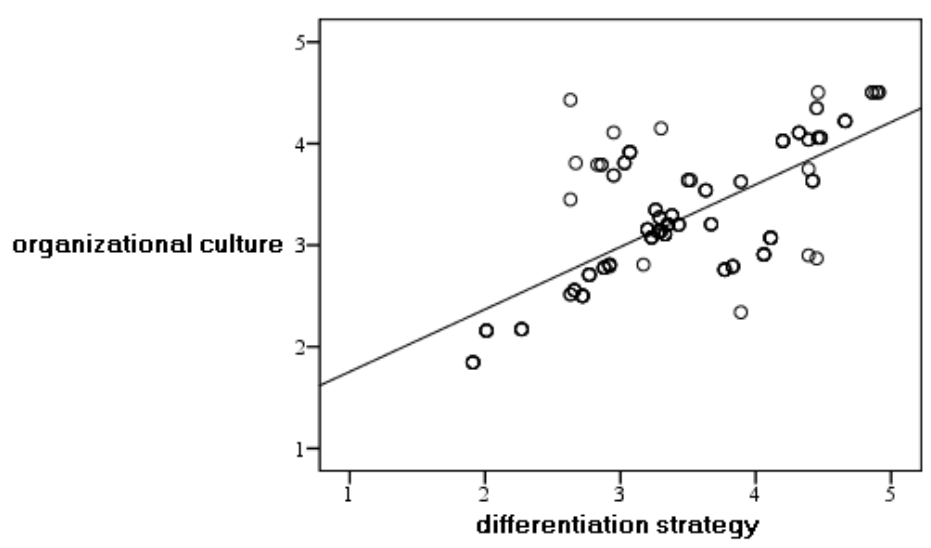

Diagram 2. Data transmittance related to differentiation strategy in relation with organizational culture

Table 5. Regression analysis of the effects of concentration strategy on organizational culture

\begin{tabular}{ccccccc}
\hline \multicolumn{2}{c}{ Variance Analysis } & \multicolumn{2}{c}{ Parameters Calculations } & & $\begin{array}{c}\text { Pearson Correlation } \\
\text { Coefficient }(\mathrm{r})\end{array}$ & $\begin{array}{c}\text { Coefficient of } \\
\text { Determination }\left(\mathrm{R}^{2}\right)\end{array}$ \\
\cline { 1 - 4 }${ }_{(151,1)} \mathrm{F}$ & $\mathrm{P}$ & Intercept & Slope & & 0.29 & $38.5 \%$ \\
\hline 98.76 & $\mathrm{p}<.001$ & 1.377 & 0.655 & & $0.5 \%$ \\
\hline
\end{tabular}

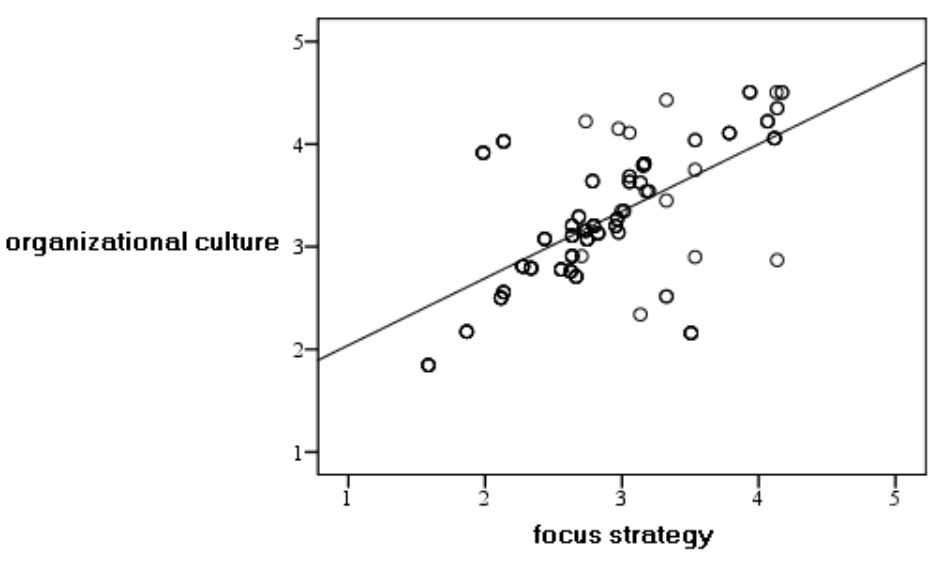

Diagram 3. Data transmittance related to concentration strategy in relation with organizational culture

Firstly, single sample t-student test was used to compare the mean of these components and the average in order to analyze and determine the condition of the components of competitive strategies. The outcomes which are mentioned in table 6 signify this fact that the mean of differentiation and lower cost strategies are meaningfully higher than the average, while the mean of concentration strategy is meaningfully lower than the average. Next, Wilcoxon Signed Rank Test was used in order to determine the rank of each differentiation and lower cost strategies in which the results show that the mean of differentiation strategy is meaningfully higher than the mean of lower cost strategy. Table 7 shows the results of this test.

Table 6. Comparison of mean of the components Porter's competitive strategies by the use of single sample t test

\begin{tabular}{cccccc}
\hline Strategy & Mean & Standard Deviation & ${ }_{(152)} \mathrm{t}$ & $\mathrm{P}_{\text {Value }}$ & Confidence Interval 95\% \\
\hline Differentiation & 3.55 & 0.82 & 7.45 & $\mathrm{p}<.001$ & $(3.71 \& 3.75)$ \\
Lower Cost & 3.77 & 0.74 & 4.86 & $\mathrm{p}<.001$ & $(3.36 \& 3.39)$ \\
Concentration & 2.96 & 0.59 & -2.87 & 0.005 & $(2.86 \& 2.76)$ \\
\hline
\end{tabular}

Table 7. Statistics of Wilcoxon test in ranking differentiation and lower cost strategies

\begin{tabular}{cc}
\hline $\mathrm{P}_{\text {Value }}$ & $\mathrm{Z}$ \\
\hline 0.002 & -3.107 \\
\hline
\end{tabular}


Single sample t-student test was used to compare the mean of these components and the average in order to analyze and determine the condition of the components of organizational culture (based on Robbins' ten variable model) at first. Table 8 shows the results of this test.

Table 8. Comparison of mean of the components of organizational culture (Robbins' model) by the use of single sample t-test

\begin{tabular}{cccccc}
\hline Robbins' ten variable model & Mean & Standard Deviation & ${ }_{(152)} \mathrm{t}$ & $\mathrm{P}$ & Confidence Interval 95\% \\
\hline Creativity & 2.99 & 0.68 & 2.78 & 0.240 & $(3.11 \& 3.54)$ \\
Risk-taking & 4.01 & 0.75 & 4.87 & $\mathrm{p}<.001$ & $(3.15 \& 3.39)$ \\
Direction & 3.74 & 0.52 & 6.57 & $\mathrm{p}<.001$ & $(3.24 \& 3.44)$ \\
Unity and coherence & 3.47 & 0.67 & 8.05 & $\mathrm{p}<.001$ & $(3.32 \& 3.51)$ \\
Management support & 3.57 & 0.74 & 5.01 & $\mathrm{p}<.001$ & $(3.27 \& 3.59)$ \\
Control & 3.56 & 0.73 & 6.55 & $\mathrm{p}<.001$ & $(3.45 \& 3.48)$ \\
Identity & 3.36 & 0.72 & 6.19 & $\mathrm{p}<.001$ & $(3.64 \& 3.48)$ \\
Reward System & 2.89 & 0.63 & -2.17 & 0.033 & $(2.99 \& 2.99)$ \\
Handling Conflict & 2.86 & 0.63 & -2.67 & 0.006 & $(2.66 \& 2.96)$ \\
Organizational Communications & 3.37 & 0.75 & 4.64 & $\mathrm{p}<.001$ & $(3.25 \& 3.67)$ \\
\hline
\end{tabular}

Results of the above test signify that the means of creativity, risk-taking, direction, management support, control, identity and organizational communication components are meaningfully higher than the average. While, the mean of reward system and handling conflict components are meaningfully lower than the average. In the next step, the Freedman Test was used in order to determine the rank of each differentiation and lower cost strategies. The results of this test show that there is a meaningful difference among the mean of the ranks of organizational culture components. Table 9 shows the results of this test.

Table 9. Freedman Test for comparing the dimensions of organizational culture based on Robbins' model

\begin{tabular}{cccc}
\hline Sample Size & Test Statistics & Freedom Degree & $\mathrm{P}_{\text {Value }}$ \\
\hline 175 & 795.00 & 9 & $\mathrm{p}<.001$ \\
\hline
\end{tabular}

Single sample t-student test was used to compare the mean of these components and the average in order to analyze and determine the condition of the components of organizational culture at first. Table 10 which shows the results of this test signifies that the mean of environmental complexity and environmental instability components is higher than the average.

Table 10. Comparison of components of organizational culture (Organic-Mechanical Model) by the use of single sample $t$ test

\begin{tabular}{cccccc}
\hline Organic-Mechanical Model & Mean & Standard Deviation & ${ }_{(152)} \mathrm{t}$ & $\mathrm{P}$ & Confidence Interval 95\% \\
\hline Environmental Complexity & 3.68 & 0.76 & 7.10 & $\mathrm{p}<.001$ & $(3.47 \& 3.70)$ \\
Environmental Instability & 3.47 & 0.82 & 7.24 & $\mathrm{p}<.001$ & $(3.59 \& 3.62)$ \\
\hline
\end{tabular}

In the next step, the Wilcoxon Signed rank Test was performed in order to determine the rank of each environmental complexity and environmental instability components of Organic-Mechanical Model. The results of this test show that there is no meaningful difference between environmental complexity and environmental instability in 0.05 level of significance. Table 11 shows the results of this test.

Table 11. Statistics of Wilcoxon Test in ranking organic-mechanical model

\begin{tabular}{cc}
\hline $\mathrm{P}_{\text {Value }}$ & $\mathrm{Z}$ \\
\hline 0.977 & -0.016 \\
\hline
\end{tabular}

Finally, the Freedman Test was used in order to compare and determine the rank of each organizational culture components (originated from both Robbins' and Organic-Mechanical Models). The results of this test show that there is a meaningful difference among the mean of the ranks of organizational culture components. Table 12 shows the results of this test. Moreover, table 13 shows the mean of the ranks of organizational culture components. 
Table 12. Results of Freedman Test in comparing the dimensions of organizational culture (Combination of two selected models)

\begin{tabular}{cccc}
\hline Sample Size & Test Statistics & Freedom Degree & $\mathrm{P}_{\text {Value }}$ \\
\hline 175 & 878.47 & 11 & $\mathrm{p}<.001$ \\
\hline
\end{tabular}

Table 13. Mean of the ranks of organizational culture components (Combination of two selected models)

\begin{tabular}{cc}
\hline $\begin{array}{c}\text { Organizational Culture Dimensions } \\
\text { (based on Robbins' Ten Variable Model) }\end{array}$ & Ranks Mean \\
\hline Creativity & 3.98 \\
Risk-taking & 6.77 \\
Direction & 8.09 \\
Unity and Coherence & 9.55 \\
Management Support & 5.45 \\
Control & 8.41 \\
Identity & 8.54 \\
Reward System & 3.01 \\
Handling Conflict & 2.00 \\
Organizational Communications & 6.50 \\
Environmental Complexity & 9.00 \\
Environmental Instability & 8.07 \\
\hline
\end{tabular}

\section{Conclusion}

Based upon the results, it seems that Iran-Khodro Company has tendency towards differentiation and decentralization framework in its competitive strategies. Therefore, according to the applied model in the research, it can be stated that the competitive strategy of the company is differentiation; Regarding the slight difference between cost leadership and differentiation strategies in this study, although that there is a combination of these two strategies in the company which shows the limitations of Porter's Model, it is more in tune with dominant conditions on Iran-Khodro Automobile market. In addition, according to the carried out analyses, a structure which is less complicated, less formal and not concentrated along with the increasing number of representatives, target markets, costumers and expanding relation with distributers is suggested due to high environmental instability. Such a structure needs establishing organic culture in the organization. By studying the components of organizational culture, it seems that there is no sufficient cooperation and justification between competitive strategy and organizational culture in some cases.

\section{Suggestions and Recommendations}

Some strategies are suggested in order to increase cooperation and justification between competitive strategy and organizational culture of various units as the followings:

Activities which follow lower cost strategy and considering this fact that this strategy wants to control expenditure and increase efficiency, it seems that the component of organizational culture system has less compatibility with such activities. Thus, it is suggested that the value criteria should be revived in such a way to improve the condition of this component in which activities of the function (such as rate of obeying rules, number of outputs, efficiency and etc.) of this strategy should have higher score in some cases.

Concerning the activities which follow differentiation strategy and considering this fact that this strategy wants to present unique and higher value to customers, it is suggested that more attention should be paid to some cases such as teaching and expanding job skills, systematic structures, more communications among organization units, sharing information with personnel, their consultant and participation, giving sufficient freedom to personnel and expecting their responsibilities as well, teaching negotiation techniques, behavior in team, explaining the responsibility of other units and groups of the organization (particularly those groups which have responsibilities related to each other) in order to improve some components like individual creativity, management support, control, reward system and tolerating conflict which have less compatibility with activities of the function of the strategy. Revising value criteria in these type of activities (like including factors such as taking responsibility in given tasks, rate of cooperation with other people of the group, rate of upgrading knowledge and skills and etc.) can be effective in improving the condition of reward system, too. 
Regarding decentralization approach to competitive strategy of the company and considering this fact that this strategy wants to present value in an extensive competitive scope, it seems that some components like management support and reward system have less compatibility with such activities. Therefore, it is suggested that a more appropriate reward system should be performed in tune with the mentioned approach by revising value criteria (and regarding some cases such as the rate of the growth of representatives' activities, expanding relation with distributers, marketing, expanding relations with customers and so on). Moreover, strategies like teaching, sharing information with personnel, consulting and having their participation can be used in order to improve the condition of management support component.

\section{References}

Ali Ahmadi, A. R. (2005). A comprehensive approach to strategic management (2nd ed.). Tolide Danesh Press.

Arabi, S. M. (2006). The letters strategic planning (1st ed.). Cultural Research Bureau of Iran (CRB).

Asemi Pour, M. J. (1996). Effective management and supervision (1st ed.). Sadan Press.

Bayan, H. (2009). Strategic Management, group of professors of management compilation (1st ed.). Public Administration Training Center.

Campbell, D. (2003). Business Strategy: An Introduction (2nd ed.). MPG Books Ltd, Great Britain.

Collins, J. M. (1990). Grand Strategy: Principles and Practices (1st ed.). Naval Institute Press.

Davari, D., \& Shanehsaz Zadeh, M. (2001). Strategic management from theory to practice (4th ed.). Ashena Press.

David, F. R. (2010). Strategic management (3rd ed.). Prentice Hall.

Dehkordy L. F., Shakhsian, F., Nawaser, K., Vesal, S. M., \& Kamel, A. (2013). Identification of factors influential in policy making and presenting a combined model of Iran's policy making, Journal of sustainable development, 6(8).

Eizi, N., Semnani, B. L., Nawaser, K., \& Vesal, S. M. (2013). The impact of application of information technology on electronic service quality. Research journal of applied sciences, engineering and technology, $6(15), 2747-2756$

Hakkak, M., Hajizadeh Gashti, M. A., \& Nawaser, K. (2014). The relationship between perceived organizational support and job satisfaction with organizational commitment. Entrepreneurship and Innovation Management Journal, 2(3), 14-202.

Hashemzadeh, G. R., Khaksar, S. M. S., Nawaser, K., \& Jahanshahi, A. A. (2011). Technological dimension of customer relationship management. Indian Journal of Science \& Technology, 4(11).

Iranzadeh, S. (2008). Management, organizational culture (1st ed.). Moallef Press.

Jahanshahi, A. A., Khaksar, S. M. S., Yaghoobi, N. M., \& Nawaser, K. (2011b). Comprehensive Model of Mobile Government in Iran. Indian Journal of Science and Technology, 4(9).

Jahanshahi, A. A., Gasthi, M. A. H., Midarmadi, S. A., Nawaser, K., \& Khaksar, S. M. S. (2011c). Study the effects of customer service and product quality on customer satisfaction and loyalty. International Journal of Humanities and Social Science, 1(7), 253-260

Jahanshahi, A. A., Nawaser, K., Khaksar, S. M. S., \& Kamalian, A. R (2011d). The Relationship between Government Policy and the Growth of Entrepreneurship in the Micro, Small and Medium Enterprises of India. Journal of Technology Management \& Innovation, 6(1), 66-76.

Jahanshahi, A. A., Nawaser, K., Paghaleh, M. J., \& Khaksar, S. M. S. (2011a).The role of government policy and the growth of entrepreneurship in the micro, small\& medium-sized enterprises: An overview. Australian Journal of Basic \& Applied Sciences, 5(6).

Jahanshahi, A. A., Pitamber, B. K., \& Nawaser, K. (2010). Issues and Challenges for Women Entrepreneurs in Global Scene with Special Reference to India. Australian Journal of Basic and Applied Sciences, 4(90), 4347-4356.

Jahanshahi, A. A., Rezaei, M., Nawaser, K., Ranjbar, V., \& Pitamber B. K. (2012). Analyzing the effects of electronic commerce on organizational performance: Evidence from small and medium enterprises. African Journal of Business Management, 6(15), 6486-6496.

Khaksar, S. M. S., Nawaser, K., Jahanashahi, A. A., \& Kamalian, A. R. (2011). The Relation between After-Sales 
Services and Entrepreneurial Opportunities: Case Study of Iran-Khodor Company. African Journal of Business Management, 5(13), 5152-5161.

Krither, R., \& Kinikj, A. (2004). Organizational Behavior (7th ed.). Mc Graw-Hill.

Markides, C. C. (1999). A Guide to Crafting Breakthrough Strategy. Harvard Business Press.

Mintzberg, H., Lampel, J., Quinn, B. J., \& Ghoshal, S. (2003). The Strategy Process. Pearson Education.

Moezzi, H., Nawaser, K., Shakhsian, F., \& Khani, D. (2012). Customer relationship management (e-CRM): New approach to customer's satisfaction. African Journal of Business and Management, 5(6), 2048-2055

Nawaser, K., Jahanshahi A. A., Mirdamadi, S. A., Khaksar, S. M. S., \& Zieaeshahabi, S. (2011b). E-CRM toward customer satisfaction: current status and future trends. Asia Pacific Journal of Research in Business Management, 2(10), 128-135

Nawaser, K., Khaksar, S. M. S., Shakhsian, F., \& Jahanshahi, A. A. (2011a). Motivational and Legal Barriers of Entrepreneurship Development. International Journal of Business and Management, 6(11).

Nixon, L. (2004). Change Management: Theory and Practice. Business Date Journal, 12(1). Retrieved from http://www.taranomco.com/wp-content/uploads/2013/11/286.pdf

Osterwalder, A. P. (2002). An e-Business Model Ontology for Modeling e-Business. Proceedings of the $15^{\text {th }}$ Bled Electronic Commerce Conference, Slovenia.

Rahmanseresht, H. (2004). Strategic management (1st ed.). Meraj Press.

Robbins, S. P. (1990). Organization Theory: Structure, Design and Theory (3rd ed.). Prentice-Hall, Englewood Cliffs, NJ.

Sadeghi, A. G., Nawaser, K., Vesal, S. M., \& Kazi, R. (2013). Which Organizational Culture Moves Towards Organizational Excellency, Asian Social Science, 9(11), 221-236. http://dx.doi.org/10.5539/ass.v9n11p221.

Schneider, S. C., \& Bars, J. L. (2002). Managing across cultures. Pearson Education.

Sorenson, B. J. (2002). The Strength of Corporate Culture and the Reliability of Firm Performance. Administrative Science Quarterly, 47.

Toosi, M. A. (1990). Participation and partnership management. Industrial Management Institute (IMI).

Vesal, S. M., Nazari, M., Hosseinzadeh, M., Shamsaddini, R., \& Nawaser, K. (2013). The relationship between labor market efficiency and business sophistication in global competitiveness. International Journal of Business and Management, 8(13), 83-92.

Wasson, R., \& Miee. (2004). Five Steps. Engineering Management (pp. 14-15). February/March.

Zomorrodian, A. (1994). Change management (strategy, application and new models) (1st ed.). Industrial Management Institute (IMI).

\section{Copyrights}

Copyright for this article is retained by the author(s), with first publication rights granted to the journal.

This is an open-access article distributed under the terms and conditions of the Creative Commons Attribution license (http://creativecommons.org/licenses/by/3.0/). 